Fecha de recepción: mayo 2014 Fecha de aceptación: mayo 2015 Versión final: julio 2016

\section{Cuerpo trazado. Contexturas orgánicas e inorgánicas}

Beatriz Ferreira Pires *

\begin{abstract}
Resumen: Las envolturas corporales hechas en la piel y a través de ella -tatuajes- o confeccionadas a partir de elementos pertenecientes al cuerpo biológico -dibujos y joyas con representaciones de calaveras, ropa hecha de cabellos- que en otros tiempos pertenecieron a ritos sagrados, hoy en día y de modo creciente, son utilizados por diseñadores de moda y de joyas y por artistas. Estas envolturas hacen evidente y ajeno lo que antes era íntimo e innato, se apartan de lo que es común. Colocan en evidencia lo que no estaba destinado a ser visto; crea contradicciones y situaciones propicias para la extrañeza. Lo extraño tiene la función de remitirnos a zonas oscuras, en las cuales lo común no es habitual. Aprender lo que en ellas existe requiere que vayamos más allá de nuestros límites y vaciarnos de nosotros mismos.
\end{abstract}

Palabras clave: Arte - cuerpo - envolturas corporales - magia - Moda piel - sagrado.

[Resúmenes en inglés y portugués en la página 339]

${ }^{(*)}$ Arquitecta, artista plástica, profesora e investigadora del Curso de Textil y Moda de la Escuela de Artes, Ciencias y Humanidades de la Universidad de San Pablo. Posee PostDoctorado (Fapesp/2009) por el programa Moda, Cultura y Arte / Centro Universitário SENAC-SP. Doctorado (Fapesp/2006) en "Educación, Conocimiento, Lenguaje y Arte"FE/Unicamp. Maestría (CNPq/2001) - IBA/Unicamp.

\title{
Introducción
}

Revestimiento exterior del cuerpo, punto inicial de la mirada del otro, y, como tal, propenso para permitir la identificación del organismo que cubre, la piel humana es utilizada, desde hace mucho tiempo, como apoyo para sobre posiciones e interferencias para conquistar aspiraciones pertenecientes a diferentes aéreas del conocimiento y de actuación. Como ser, en el área sociocultural - apariencia física, identificación individual y colectiva. El área ritualista relacionada con la magia y lo sagrado y el área artística, relacionado a trabajos que tienen al cuerpo como soporte, como objeto o como protagonista de la acción desarrollada/presentada. 
Tejido orgánico flexible, la piel es un agregado de células, envoltorio que circunscribe los limites del cuerpo, separa lo interno de lo externo y delimita lo uno del todo. Dotado de la capacidad de regeneración y con espesores que varían de $0.5 \mathrm{~mm}$ a $4.0 \mathrm{~mm}$, compuesto por tres finas camadas denominadas epidermis (externa), dermis (intermediaria) e hipodermis o tejido subcutáneo (interna) las cuales son constituidas por diferentes niveles de superficies. Esta construcción /sobre posición da origen a una superficie que, a pesar de ser aparentemente homogénea, posee una complexión formada por incontables protuberancias y depresiones. Frontera captadora de estímulos táctiles, cuya cualidad de ser permeable unilateralmente, de dentro para fuera, asegura a ésta las funciones de actuar, concomitantemente, como termorreguladora del organismo y de impedir el ingreso, al interior del mismo, de elementos que le sean extraños.

Cuando la piel se presenta desnuda de elementos materiales sobrepuestos en ella, ésta expone marcas originadas por una sumatoria de factores que incluyen: tiempo cronológico, referente a la edad del individuo. Circunstancias ambientales, referentes al local donde éste reside, como geografía, clima, etc. Hábitos y funciones desarrollados en el cotidiano, como higiene, alimentación, tipo de trabajo, otras actividades, etc. Finalmente, posibles lesiones, causadas por accidentes y enfermedades.

Cuando la piel se presenta desnuda de elementos inmateriales sobrepuestos en ella, de acuerdo con la reflexión sobre la mitología cristiana presentada por el filósofo italiano Giorgio Agamben, en el texto "Nudez", ésta retira al hombre del dominio de lo sagrado y lo coloca bajo el dominio de lo secular.

Para desarrollar este raciocinio, Agamben parte del episodio descrito en Génesis sobre la expulsión de Adán y Eva del paraíso, en el cual ambos, a pesar de estar desnudos, sólo se ven desnudos después de haber comido el "fruto del árbol del bien y del mal". La constatación de la desnudez después de haber ingerido el fruto viene de la idea de que antes de ejecutar este acto, Adán y Eva estaban cubiertos por la Gracia de Dios. Una vez descubiertos, ellos entran en el dominio de la naturaleza.

Es la supresión del cambio que, de acuerdo con el mito melanesio del origen de la muerte, descrito por Mircea Eliade en "El Conocimiento Sagrado de Todos los Tiempos", transforma la condición inmortal del ser humano a la de ser susceptible a la muerte.

"Al comienzo los hombres no morían, pero cuando llegaban a cierta edad eliminaban la piel, como hacen las cobras y los cangrejos y se volvían jóvenes nuevamente. Después de un cierto tiempo, una mujer que estaba quedándose vieja fue a un regato para cambiar de piel. Tiró la piel vieja al agua y notó que al ser llevada la piel por la corriente del agua quedó atrapada en un tronco seco. Volvió a su casa donde había dejado a su hijo y éste se negó a reconocerla y llorando dijo que su madre era una mujer vieja y no esta joven extraña. Así, para calmar al niño, la madre volvió al regato y volvió a vestir la piel eliminada. Desde entonces los seres humanos dejaron de eliminar la piel y comenzaron a morir."

De acuerdo a lo descrito, los hombres no eran seres sujetos a la muerte. La inmortalidad de nuestra especia era asegurada por la capacidad de cambiar nuestra piel envejecida por una piel más joven.

Analizando lo expuesto podemos sugerir que, la substitución o el rejuvenecimiento de la envoltura ocasiona la inmortalidad del organismo bajo su protección. Esta substitución 
debe estar vinculada, o debe ocasionar, si no el rejuvenecimiento global del sistema orgánico que envuelve, por lo menos la estagnación del proceso natural de envejecimiento. Este vínculo, aunque no está descrito en el mito, tiene que ser evidente, ya que la simple restitución del aspecto joven no asegura el buen funcionamiento del organismo.

Siguiendo esta línea de raciocinio, nos es posible decir que el rejuvenecimiento de la envoltura, de lo que era aparente y visible, garantizaba simultáneamente el rejuvenecimiento de lo que estaba en su interior y lo que la sustentaba. Además, el rejuvenecimiento de la envoltura ocasionaba el no reconocimiento del individuo que la portaba. Inclusive en circunstancias, en las cuales, el cambio de piel para lograr el rejuvenecimiento era una práctica cotidiana, de rutina y usual; ocurrió que el no reconocimiento del individuo partió de un ente extremadamente próximo a éste, el hijo.

El factor principal y decisivo apuntado por el mito para asegurar la condición de inmortalidad es, precisamente, hacer desaparecer las particularidades físicas, aniquilar los trazos distintivos del individuo.

Al dejar el viejo tegumento de lado, el individuo aparta de sí los soportes visibles -piel, pelos, cabellos, uñas- de las particularidades físicas que adquirió a lo largo de su vida. El nuevo tejido se presenta como una superficie apta para recibir otras inscripciones sobre ella, que pueden ser, o no, análogas o comparables con las anteriores.

El relato melanesio no deja claro si la substitución de la piel ocurría periódicamente o una única vez. Pero, nos induce a pensar que acontecía de un modo cíclico a cada determinado número de años.

\section{Piel. Mapa histórico genético del individuo.}

Como dijimos anteriormente, volver a tener aspecto joven debido a la restitución de la piel, implica haber retirado, o disminuido, las marcas inscritas en ella a lo largo de la vida. Considerando la piel como un mapa histórico genético, que posee la capacidad de almacenar y exponer, a través de las inscripciones que le fueron impresas, parte de las experiencias vividas por su portador; podemos decir que la retirada de tales inscripciones, sugiere la extinción de los hechos, acciones, pensamientos, sensaciones y sentimientos que las produjeron y actúa como un elemento aniquilador de la memoria y de la identidad. En el mito, la identidad del individuo se torna irreconocible sin las marcas/ inscripciones que testifiquen, comprueben y ofrezcan la veracidad física de la historia vivida por el individuo.

Además de las marcas corporales hasta ahora mencionadas, las cuales son contraídas independientemente del deseo de quien las porta; existen aquellas que son adquiridas por intervención, sea esta por voluntad del individuo, o de la tradición a la cual él pertenece. Cuando, oriundas de rituales de transición, estas marcas - que son uno de los cuatro preceptos establecidos por las sociedades sin escritura para la realización de los mismos, siendo los otros tres: ser una cosa física, ocasionar dolor, verter sangre o por lo menos dejar 
al organismo en la inminencia de hacerlo - tienen la función de recordar al individuo el cambio de estado, situación, cualidad o circunstancia que sufrió cuando participo de este tipo de ceremonia.

En este contexto, la piel se torna en el local donde son impresas las marcas corporales resultantes, portadoras y protectoras de las acciones y reacciones vividas y generadas por cada individuo a lo largo de su existencia.

\section{Modificaciones corporales}

Contemporáneamente, en nuestra sociedad, podemos distinguir básicamente dos posicionamientos diferentes y contrarios, con referencia al modo de hacer y a la adquisición de interferencias corporales. Si bien, uno incentiva que el individuo se aproxime lo máximo posible al padrón de belleza momentáneamente establecido -padrón este que sufre variaciones y se altera conforme a periodos históricos y a culturas a las que pertenece- $y$ otro, que privilegia y favorece la singularidad. Estimula que el individuo se distancie estéticamente, no sólo del padrón estipulado, pero también de la especie a la cual pertenece y modifique su silueta de acuerdo a su deseo.

Para los adeptos al primer posicionamiento caben todas las formas de interferencia, desde la más simple aplicación de cremas hasta la realización de arriesgadas intervenciones quirúrgicas para incorporar implantes estéticos que reproduzcan formas humanas. Todas éstas hechas con la finalidad de eliminar trazos y particularidades que no correspondan a las formas estandarizadas, de eliminar las marcas adquiridas con el tiempo y de adecuar la silueta a formas, dimensiones y proporciones correspondientes al modelo a ser seguido. Para los adeptos del segundo posicionamiento caben -de forma diametralmente opuestatodas las manipulaciones y técnicas que aseguran la realización y permanencia de intervenciones que insieran en sus cuerpos elementos, formas, texturas y colores que en nada se asemejan con las innatas, tales como: tatuajes, piercing (perforaciones), escarificación e implantes estéticos que no reproducen formas humanas.

Aunque no sea posible precisar la procedencia de ninguna de las técnicas pertenecientes al grupo de las que no reproducen los componentes innatos y el hecho de que todas ellas se hayan originado en sociedades ancestrales nos hace suponer -baseados en la forma entrelazada que los elementos anatómicos, las acciones fisiológicas, los actos y objetos del cotidiano se juntaban con las esferas de la magia y lo sagrado en estas sociedades- que todas estas técnicas tuvieron su origen asociado a procedimientos pertenecientes a estas esferas. Es importante resaltar que, así como las intervenciones corporales realizadas por los adeptos del primer posicionamiento no son percibidas como indumento; las realizadas por los adeptos del segundo posicionamiento lo son.

Esta diferencia en la forma de percibirlas está asociada al hecho de que, mientras las del primer tipo son realizadas a través de la substitución o adecuación de elementos, dimensiones e formatos anatómicos innatos, por ejemplo el implante de senos, pantorrillas o glúteos de silicona; las del segundo tipo son realizadas a través de la introducción en el 
cuerpo de elementos ajenos a la especie por ejemplo implantes en la forme de cuernos, figuras geométricas, etc.

Siguiendo esta línea de raciocinio, en el caso especifico de las modificaciones corporales, acrecentar a la silueta algo que no le es propio hace que nos distanciemos de la idea/imagen de substitución y adecuación y nos aproximamos a la Idea de sobre posición y revestimiento. Dentro de este contexto, cuando en el mito melanesio descrito anteriormente el individuo es dotado de la capacidad tanto de substituir ("una mujer que estaba envejeciendo fue a un regato para cambiar de piel.”), como de vestir o desvestir su tegumento -el conjunto formado por la piel y sus anexos: pelos, cabellos y unas ("la madre volvió al regato en busca de su tegumento eliminado y volvió a vestirlo nuevamente."), el tegumento pasa a ser percibido como algo que es intrínseco al cuerpo y por tanto pasible de substitución, como también como algo que le es extrínseco, por tanto pasible de ser acrecido, sobrepuesto.

En la condición de extrínseco, el tegumento pasa a ser comprendido como un conjunto de elementos que cubre, que reviste la carne, la sangre, el plasma, los músculos, los huesos, los cartílagos y las vísceras, en este caso legítimos componentes del cuerpo.

Si analizamos esta cuestión bajo la óptica de la localización espacial de los componentes del cuerpo, aquellos que se posicionan en el margen y por tanto establecen el límite del cuerpo con lo externo - piel, pelos, cabellos y unas- asumen por su propia localización las funciones de mediar el contacto entre lo interno y lo externo y de proteger lo que está localizado en el lado interno.

A lo interno cabe lo que está oculto, abrigado, protegido; a lo externo lo que está revelado, desvendado, explicito. Cuando el tegumento es cubierto o revestido por cualquier tipo de envoltura -pintura corporal, tatuajes, escarificación, etc.- lo que antes estaba expuesto muda de posición y pasa a estar total o parcialmente escondido, oculto, camuflado.

En estas circunstancias lo que anteriormente era absoluto en las funciones de mediar entre lo interno y lo externo y de proteger lo interno, pasa a desempeñar la primera función de forma parcial y a ser -integral o parcialmente- protegido por la envoltura que le es sobrepuesta. Recientemente el mundo de la moda incorporo al conjunto de sus colaboradores un modelo cuya piel presenta la imagen de alguien que se vació de sí mismo.

Zombie Boy es el nombre por el cual el canadiense Rick Genest es conocido. El recubrió buena parte de su cuerpo con tatuajes -todos ellos hechos con pigmento de color negroque en su grande mayoría representan el interior de su cuerpo: huesos, músculos, órganos, dientes. Todos estos elementos anatómicos diseñados sobre la piel de Genest están dispuestos conforme a la localización natural. Los huesos de la columna vertebral están representados sobre la columna vertebral; los de la mano, sobre la mano y así por delante. $\mathrm{Al}$ atenerse al correcto posicionamiento y a las dimensiones de los elementos anatómicos representados y al transformar su piel en una especie de radiografía de sí mismo, Genest nos coloca frente a lo interno del cuerpo; aquello que debía estar oculto vino a la luz. Este interno, que diseñado junto con los tatuajes de algunos vermes -que son los otros diseños inscritos en su cuerpo- apunta para la putrefacción del cuerpo, para la mortalidad de la especie.

En el mito melanesio, el cambio del tegumento que no altera la disposición/orden espacial -dentro/fuera- de los componentes que constituyen el organismo pero que borra las singularidades inscritas en la piel del individuo, asegura la inmortalidad del hombre. Mien- 
tras que, la inversión del orden espacial hecha por Genest, que da visibilidad a los huesos -componentes más internos y los mas durables del cuerpo- y por esto considerados los elementos que asemejan todos los miembros de la especie, expone su finitud.

Haciendo un paréntesis, según el mito Cristiano de la creación, los huesos dieron origen al segundo ser humano: Eva. Varios otros mitos, pertenecientes a diferentes civilizaciones, como por ejemplo: la nórdica, tibetana, iraniita, etc. atribuyen a los huesos la facultad de hacer volver los muertos a la vida.

Para todos los pueblos que siguen el chamanismo, huesos y esqueletos son elementos con gran carga simbólica.

"Ellos guardan en si la “Vida total' en continua regeneración”. En otras palabras, los huesos -según Eliade- "contienen todo el pasado y todo el futuro, no sólo del individuo a quien pertenecen, pero de la vida como un todo -denominada por los chamanes- "Gran Vida”.

Volviendo a Zombie Boy, es interesante notar que la superficie de las figuras de los huesos, músculos, dientes tatuados en su cuerpo es compuesta por el color natural de su piel. El pigmento negro es usado solamente para delinear estas figuras y representar el espacio vacío entre ellas y la profundidad del interior del cuerpo.

\section{Envolturas y adornos corporales. Objetos con la función de potencializar y proteger.}

Más allá de las motivaciones cotidianas de uso, las envoltura y adornos corporales fueron y son empleadas por diversas sociedades con el intuito de potencializar dones y cualidades innatos de sus usuarios y proteger a los mismos de maleficios inmateriales que puedan venir a acometerles.

Dentro de esta perspectiva, las envolturas que potencializan los dones innatos de los individuos que las portan sobre sus pieles o inseridas en éstas tienen su origen en sociedades sin escritura y existen desde tiempos inmemorables. Por ejemplo, un cazador de una tribu, al adquirir en una ceremonia chamanista sagrada una determinada marca corporal -tatuajes, escarificación, etc.- pasa a tener la capacidad de desempeñar al máximo su función de cazador. Para estas sociedades, este tipo de marca cultural que se denomina complementar, garante a su portador una eficiencia máxima en las funciones que desempeña.

También originarios de civilizaciones ancestrales, los que pertenecen a la segunda categoría -las envolturas que protegen a sus usuarios de supuestos maleficios inmateriales- no desempeñan la función de cubrir materialmente el cuerpo de las intemperies y de las acciones que le puedan causar molestias, lesiones y perjuicios; más, la de resguardar la integridad del individuo que los porta, de posibles efectos nocivos y perjudiciales que le hayan sido destinados, como ser envidia -invidia en latín, que quiere decir "que tiene o lanza mal de ojo"-, infortunio, etc. Tal idea otorga a determinadas envolturas y adornos cualidades originadas en las esferas de la magia -técnica animista desarrollada por imitación, similitud y contagio, con la difícil función de realizar toda especie de deseos- y de lo sagrado. 
Siguiendo esta línea de pensamiento, la utilización de adornos corporales con la intención de obtener protección fue una practica difundida durante la Edad Media entre lós seguidores de la religión Cristiana, quienes utilizaban determinados adornos que recibieron el nombre de relicarios - reliquiae en latín, que quiere decir: "restos, residuos de alguna cosa". Lo que diferenciaba las joyas-relicarios -confeccionados en formas de pendientes, broches, etc.- de las demás joyas era el hecho de que éstas contenían en su interior partes de ropa o de objetos de martirio que supuestamente habrían tenido contacto con el cuerpo de un santo, o partes que supuestamente eran del cuerpo del santo como huesos, cabellos, unas o fluidos corporales como sangre, lagrimas, etc.

Denominados reliquias, todos estos objetos eran dotados de gran valor; conforme resalta Schimitt en el libro El cuerpo de la imágenes, eran las reliquias que aseguraban y legitimizaban la presencia corporal de entes divinos entre los hombres.

Entre las partes del cuerpo que eran más usadas para colocarlas dentro de los relicarios estaba el cabello. La utilización de este componente corporal puede ser justificada por la abundancia de este elemento en relación a los otros que componen el cuerpo. El hecho de que varios relicarios eran rellenados con mechas de cabellos de un mismo santo, aseguraba una especie de legitimidad a la joya.

Poseer una de estas joyas colocaba a su propietario en una posición privilegiada, tanto en relación a la esfera sagrada ya que, la proximidad con la reliquia potencializaría la protección que el santo dispensaría; como en relación a la esfera secular ya que, su posesión indicaría un status diferenciado.

Con anterioridad a la religión Cristiana y a las reliquias, los objetos destinados a intensificar la protección personal y/o potencializar los dones innatos pertenecían a la esfera de la magia y eran conocidos como talismanes. Esta semejanza acabo por desacreditar el uso de joyas que llevaban reliquias.

\section{Envolturas y adornos hechos con partes del cuerpo. De la esfera de la magia y de lo sagrado para lo profano.}

En nuestra sociedad la utilización de elementos provenientes del cuerpo humano en la confección de envolturas, accesorios o adornos corporales que, ancestralmente habitaban las esferas de la magia y de lo sagrado, es frecuentemente presentada por creadores de moda y diseñadores de joyas que restringen tal utilización fundamentalmente a procedimientos relacionados a la apropiación y a la reproducción -bi o tridimensional: estampas, aplicaciones en bajo y alto relieve, objetos- de sus formas y/o texturas.

Estos elementos, aunque desconectados de las referidas esferas - de la magia y de lo sagrado- poseen fuerte contenido simbólico, despiertan en sus espectadores -con mayor o menor intensidad- sensaciones distantes de las comunes y que transitan dentro de una gama que van del extrañamiento a la repulsión.

A seguir haremos una breve relación sobre la utilización contemporánea, en las artes y en la moda, de los elementos corporales que citamos anteriormente: cabellos y huesos. 


\section{Cabellos}

Destinados a proteger la piel y definidos como un conjunto de pelos altamente resistentes a la tensión, extremadamente sensibles y totalmente impermeables, los cabellos poseen una estructura linear, fina y alargada; estas características se deben a su composición de células queratinizadas, es decir células muertas. Gracias a ellas, los cabellos pueden ser cortados sin que sintamos dolor. El conjunto de estas características permitió que nuestros ancestrales los utilizaran para hacer experimentos para hacer tejidos.

El facto de que el cabello mezcle en su composición células vivas y muertas refuerza el rol de sus significados simbólicos que, además de otros atributos, le asignan ser "la morada del alma, o de una de las almas". Esta atribución confiere a este elemento corporal la capacidad de actuar como almacenador de las características, cualidades y memorias del individuo a quien pertenece o perteneció.

Actualmente el comercio de cabellos humanos representa un mercado en expansión que no solo ofrece diferentes tipos de apliques capilares como también para la confección de ropas, zapatos, bolsas y accesorios utilizados principalmente en el campo de las artes, ya sea en funciones, shows y esculturas. También, en trabajos como el de la dupla de diseñadores ingleses Mariana Fantich e Dominic Young, presentado en 2011, intitulado: "Apex Predator. Suit. Sculture", que consiste en un terno, completamente, revestido de largas hebras de cabello humano. O el trabajo realizado por la artista visual americana Adrienne Antonson en el cual hebras de cabello son trenzadas para constituir un encaje con el cual la artista -que transita en las aéreas de la moda y la escultura-confecciona sus piezas: un par de botas, un par de guantes, suspensorio, bolsa, sostén, gafas.

\section{Huesos}

El esqueleto óseo, aparato indispensable para la locomoción e imprescindible para la sustentación del cuerpo, esta constituido -cuando adulto- por doscientas y seis piezas, que presentan formas, volúmenes y dimensiones diferentes conforme a la parte del cuerpo a la cual pertenecen: cabeza, tronco, miembros superiores, miembros inferiores. Cada una de esas piezas es formada por dos substancias provenientes de diferentes dominios: uno orgánico, formado por proteínas y glúcidos; otro orgánico, compuesto principalmente por fosfato e carbonato de calcio y fosfato de magnesio.

La capacidad de regenerar la vida que les es atribuida, está intrínsecamente vinculada al facto de que los huesos constituyen la parte más durable, inapagable e inmutable, por tanto la menos extinguible de la estructura física de la especie humana y de varias especies animales. Tal característica, que los torna pasibles de representar la materialización de la vida, induce a la creencia -oriunda de antiguos pueblos cazadores y pastores- que los ven, conforme a Eliade como la ultima fuente de la vida.

Ampliamente utilizados por la esfera de la moda y del diseño de joyas, los huesos aparecen en inúmeros tipos de indumentos idealizados y confeccionados por diversos profesionales de estas áreas. Por ejemplo, podemos citar el vestido esqueleto hecho en 1938 por la estilista italiana Elsa Schiaparelli (1890-1973). La pieza, que es la representación tridimensional 
de la columna vertebral y de tres pares de costillas, tuvo su producción vinculada a la utilización de formas acolchonadas.

Entre los ejemplos producidos más recientemente, seleccionamos la colección masculina intitulada: "Anatomical Couture", desarrollada por la joven estilista inglesa Katie Eary, para el periodo primavera/verano de 2010.

Hicimos esta selección debido a dos particularidades presentes en esta colección, que utilizo para su confección recursos bi y tridimensionales, concebidos y ejecutados respectivamente, a través de estampas impresas y de piezas moldadas a partir de la reproducción de partes del esqueleto, venas, músculos y órganos.

La primera particularidad tiene que ver con la alternativa escogida por la estilista de presentar cada uno de los elementos corporales elegidos para componer las piezas, en su correcta localización espacial. La segunda se refiere al correcto posicionamiento de los elementos en cuento a la orientación espacial, en relación a la dirección, como también en relación al sentido.

Estas particularidades, que hacen que los elementos representados en cada una de las piezas se sobrepongan exactamente en la parte de la anatomía a la que pertenecen, transforman la ropa en una especie de radiografía colorida del cuerpo que cubren.

Así como la piel tatuada del artista/modelo Zombie Boy, las piezas de la colección "Anatomical Couture" de la estilista Katie Eary invierten, a través de la representación, el orden natural entre lo que está dentro y lo que esta fuera, entre lo interior y lo exterior del cuerpo; nos presentan sobre la superficie externa una supuesta imagen de estructura interna corporal.

\section{Cuerpo trajeado por sobre posiciones de distintos órdenes}

Estar vestido implica tener algo sobre el cuerpo. Algo que lo envuelva completa o parcialmente, y como tal conserva al cuerpo, por abajo, por dentro. Al dentro pertenece lo intimo, el núcleo, lo profundo, lo minucioso.

$\mathrm{Al}$ interior de las vestes se encuentra el cuerpo delimitado por la epidermis. Al interior de la epidermis se encuentra la dermis, la hipodermis, la carne, los bulbos pilosos, los huesos, fluidos, etc.

Veste y epidermis, envolturas depositarias de ambientes recónditos que el observador desvela conforme al grado de aproximación e invasión.

Cuando elementos que componen el cuerpo son utilizados para revestirlo o adornarlo se rompen las relaciones entre dentro y fuera, entre lo congénito y lo desnatural y lo que antes era íntimo e innato se vuelve manifiesto y ajeno. Hacer evidente lo que no estaba destinado a ser visto crea contradicciones, situaciones inusuales propiciadoras de extrañamiento.

Lo extraño nos remite a zonas nebulosas, en las que -con mayor o menor intensidad- lo previsto, lo común y el inicio no es habitual.

Aprender lo que en ellas hay, requiere ir más allá del margen, vaciarse de sí. 


\section{Referencias Bibliográficas}

Agamben, G. (2010). Nudez. Lisboa: Relógio D’Água.

(2007). Profanações. São Paulo: Boitempo.

Bíblia Sagrada. (1971). São Paulo: Ave Maria Ltda.

Chevalier, J. E Gheerbrant, A. (2002). Dicionário de Símbolos. Rio de Janeiro: José Olympio.

Eliade, M. (2005). O Conhecimento Sagrado de Todas as Eras. São Paulo: Mercuryo.

(1988). Xamanismo e as Técnicas Arcaicas do Êxtase. São Paulo: Martins Fontes.

Façanha, Astrid E Mesquita, Cristiane (Org.). (2013). Styling e Criação de Imagem de Moda São Paulo: SENAC.

Pires, B. Ferreira. (2013). Digressões sobre Vestes Confeccionadas com Materiais Biológicos.

Anais $1^{\circ}$ CONTEXMOD - Congresso Científico Têxtil e de Moda. Realizado em São Paulo entre 16 e 18 de Abril de 2013.

(2012a). Dos Ossos - de suas Representações e Aproveitamentos/Utilizações. Anais $8^{\circ}$ colóquio de moda. Rio de Janeiro: SENAI/CETIQT.

(2012b). Tessituras Epidérmicas, Têxteis, Visíveis e Não Visíveis - Digressões sobre Corpo $\mathrm{Nu}$, Vestido, Revestido $1^{\circ} \mathrm{CIMODE}$ - Congresso Internacional de Moda e Design. Lisboa. (2009a). Corpo Inciso, Vazado, Transmudado - Inscrições e Temporalidades. São Paulo: Annablume.

(2009b). Corpos Insólitos - Adensadores de Tempos, Reveladores de Longínquas Memórias. Pós-doutorado em Moda Cultura e Arte. Centro Universitário Senac/SP - Faculdade de Moda.

(2005). O Corpo como Suporte da Arte - Piercing, Implante, Escarificação,

Tatuagem. São Paulo: Senac.

Schimitt, J.-C. O Corpo das Image. 
Summary: Body wraps made in the skin and through it -tatoos- or made from elements belonging to the biological body -drawings and jewelry with skulls, clothing made from hair- that once belonged to sacred rites today and increasingly, they are used by fashion and jewelry designers and artists. These wraps make it obvious and oblivious what was once intimate and innate, deviate from what is common. Placed on evidence that was not meant to be seen; creates contradictions and favorable situations for strangeness. The strange thing has the function of referring to dark areas which usually is unusual. Learn what is in there requires us to go beyond our limits and empty ourselves.

Keywords: art - body - body wraps - magic - sacred - skin fashion.

Resumo: As envolturas corporais feitas na pele e através dela -tatuagens- ou feitas a partir de elementos pertencentes ao corpo biológico - desenhos e jóias com representações de caveiras, roupa feita de cabelos - que em outros tempos pertenceram a ritos sagrados, hoje, e de modo crescente, são utilizados por designers de moda e de jóias e por artistas. Estas envolturas fazem evidente e alheio o que antes era íntimo e inato, se apartam daquilo que é comum. Põem em evidencia o que não estava destinado a ser visto, creia contradições e situações propícias para a estranheza.

O estranho tem a função de nos remitir as zonas escuras, nas quais o comum não é habitual. Aprender o que existe nelas requer ir mais lá dos nossos limites e vaziar-nos de nós mesmos.

Palavras chave: arte - corpo - envolturas corporais - magia - moda pele - sagrado. 